\title{
Pemanfaatan Refugia dalam Meningkatkan Produksi Tanaman Padi Berbasis Kearifan Lokal
}

\author{
Utilization of Refugia to Increase Rice Production Based on Local Wisdom
}

\author{
${\text { Icuk Muhammad Sakir }{ }^{1 *} \text {, Desinta Desinta }}^{2}$ \\ ${ }^{1}$ Program Studi Komunikasi, Sekolah Tinggi Ilmu Sosial dan Politik, Candradimuka, \\ Palembang, Sumatera Selatan 30127 \\ ${ }^{2}$ Pengendali Organisme Pengganggu Tumbuhan (POPT), UPTD Balai Perlindungan \\ Tanaman dan Hortikultura (BAPERLINTAN), Sumatera Selatan 30961 \\ ${ }^{*}$ Penulis untuk korespondensi: icuksakir@stisipolcandradimuka.ac.id
}

\begin{abstract}
The purpose of this study was to determine the utilization of refugia as a natural enemy of rice pest organisms in order to increase rice production sustainably. The study was conducted on a 3-hectare plot of land in Pemulutan Ulu Village, Pemulutan District, Ogan Ilir Regency, South Sumatra. The types of refugia that were used: sunflowers (Helianthus annuus), sesame (Sesamum indicum), zinnia flowers (Zinnia sp), yellow ray flower (Cosmos caudatus) and marigold flower (Tagetes $\mathrm{sp}$ ). The exploratory method was used with a cross sectional approach to analyze the intensity of the existence of natural enemies and rice pest disruptors, thus correlating with rice production. Observations were carried out for 18 weeks at 3 points with an area of 3 hectares. The rice varieties were used Ciherang (points A and C) and IR 42 (point B). The results showed an intensity of abundance of natural enemies or predators as many as 378 while the intensity of pests was 54 animals. The yield of rice was 8 tons/hectare, 8.3 tons/hectare and $\mathrm{C}$ is 8.1 tons/hectare for point $\mathrm{A}, \mathrm{B}$ and $\mathrm{C}$ respectively. Utilization of refugia in rice plants was able to increase rice production by $15.1 \%$.
\end{abstract}

Keywords: refugia, natural enemy, rice production

\begin{abstract}
ABSTRAK
Tujuan penelitian ini adalah untuk mengetahui pemanfaatan refugia sebagai musuh alami organisme pengganggu tanaman padi sehingga mampu meningkatkan produksi padi secara berkesinambungan. Penelitian dilakukan pada petak tetap seluas 3 hektar di Desa Pemulutan Ulu, Kecamatan Pemulutan, Kabupaten Ogan Ilir, Sumatera Selatan. Jenis refugia yang digunakan adalah bunga matahari (Helianthus annuus), wijen (Sesamum indicum), bunga kertas (Zinnia sp), kenikir (Cosmos caudatus) dan bunga tahi ayam (Tagetes sp). Metode penelitian yang digunakan adalah exploratory research dengan pendekatan cross sectional untuk menganalsis intensitas keberadaan musuh alami dan organisme pengganggu tanaman padi, sehingga berkorelasi dengan produksi tanaman padi. Pengamatan dilakukan selama 18 minggu pada 3 titik dengan luas hamparan 3 hektar. Varietas padi yang digunakan adalah Ciherang (titik A dan C) dan IR 42 (titik B). Hasil penelitian menunjukkan intensitas kelimpahan musuh alami atau predator sebanyak 378 ekor sedangkan intensitas hama sebanyak 54 ekor. Hasil tanaman padi pada titik A adalah 8 ton/hektar, titik B sebanyak 8,3 ton/hektar dan titik C sebanyak 8,1 ton/hektar. Pemanfaatan refugia pada tanaman padi mampu meningkatkan hasil produksi sebesar $15,1 \%$.
\end{abstract}

Kata kunci: refugia, musuh alami, produksi padi 


\section{PENDAHULUAN}

Pengendalian Organisme Pengganggu Tanaman (OPT) secara alami bergantung pada kelestarian agroekosistem dan komponen lokasi pertanaman. Organisme yang sering menyerang pada tanaman padi antara lain hawar daun bakteri, busuk batang, penyakit tungro, penyakit bercak daun, penyakit busuk pelepah daun, dan penyakit fusarium. Untuk membasmi penyakit pada tanaman padi tersebut, petani rata-rata menggunakan pestisida sebagai pembasmi instant untuk oganisme pengganggu tanaman lahan pertanian. Pestisida sangat berbahaya bagi kesehatan petani, masyarakat, dan mahluk hidup lainnya. Pemakaian pestisida secara terus menerus berdampak pada tingginya cost bagi petani karena dapat membunuh organisme yang bermanfaat sebagai musuh alami pada hama tanaman padi. Berdasarkan studi literatur dampak dari penggunaan pestisida akan mengakibatkan Multiple myeloma, sarkoma, kanker prostat dan pankreas, kanker rahim, pankreas serta Hodgkin (Alavanja et al., 2004)

Dampak negatif lain pada penggunaan pestisida adalah tanaman jadi rusak, pertumbuhan tanaman tidak normal, nutrisi makanan terkontaminasi dengan pestisida, predator musul alami berkurang, muncul spesies hama baru, perawatan tanaman tidak ekonomis, dan memburuknnya kondisi lingkungan akibat aplikasi bahan kimia sintetis yang tidak terkendali. Oleh karena itu, petani dianjurkan untuk memanfaatkan refugia sebagai solusi musuh alami untuk menekan populasi organisme pengganggu tanaman. Refugia adalah wadah untuk perlindungan bagi musuh alami dan predator yang bermanfaat bagi tanaman padi (Altieri \& Letourneau, 1982). Refugia dapat mendukung kegiatan konservasi sebagai pilihan dalam menjaga agroekosistem pada lahan pertanian (Allifah et al., 2013).

Refugia dengan warna mencolok merupakan tanaman yang mudah dibudidayakan sebagai tempat mikrohabitat serta organisme tertentu. Pada ekosistem lahan pertanian, keberadaan mikrohabitat buatan yang baik adalah pada pinggiran atau tanggul pada areal pertanian (Sam et al., 2008). Keberadaan mikrohabitat dan berbagai macam hama berdampak pada banyaknya Arthropoda di ekosistem sawah (Addina et al., 2013).

Pengendalian hama dengan cara bercocok tanam seperti pemanfaatan tanaman pinggir atau tanaman perangkap, dapat mendorong stabilitas ekosistem sehingga populasi hama dapat ditekan dan berada dalam kesetimbangannya. Jenis tanaman pinggir yang dipilih harus mempunyai fungsi ganda yaitu, disamping sebagai penghalang masuknya hamake pertanaman pokok, juga sebagai tanaman refugia yang berfungsi untuk berlindung sementara dan penyedia tepung sari untuk makanan alternatif predator, jika mangsa utama populasinya rendah atau tidak ada di pertanaman pokok. Teknik bercocok tanam seperti penanaman tanaman pinggir dapat mendorong konservasi musuh alami seperti predator (Mahmud, 2006). Refugia dapat meningkatkan peluang lingkungan musuh alami dalam pengendalian hama yang mengganggu tanaman padi (Allifah et al., 2013). Refugia adalah tumbuhan yang sangat bagus dan mudah untuk dibudidayakan sebagai mikrohabitat musuh alami pada tanaman. Musuh alami dangat menikmati keanekaragaman tumbuhan refugia karena bermanfaat untuk microhabitat. Suatu konsep pemecahan masalah yang dapat diterapkan dalam pengendalian hama adalah dengan cara menanam tanaman yang digunakan sebagai refugia sehingga konservasi predator dapat terus terjaga (Purwantiningsih et al., 2012). Tanaman refugia memiliki cirri; tanaman memiliki bunga dan warna mencolok, regenerasi tanaman cepat dan berkelanjutan, benih mudah diperoleh, mudah ditanam, dan bisa ditanam secara tumpang sari dengan tanaman lain. (Wahyuni, 2013) mengemukakan tumbuhan berbunga yang dijadikan tanaman refugia diharapkan dapat menjadi tempat perlindungan serta sebagai 
penyedia pakan bagi predator dari hama tanaman padi. Makanan yang didapatkan predator dari tumbuhan berbunga adalah madu dan nektar dari bunga serta serangga hama yang bersembunyi pada tumbuhan tersebut. Menurut (Arcury \& Quandt, 2003), selain dapat memperoleh madu dan nektar dari tumbuhan berbunga yang didatanginya, predator juga dapat menemukan mangsa yang bersembunyi di tumbuhan berbunga tersebut.

Tumbuhan berbunga berkemampuan memikat banyak musuh alami karena berfungsi sebagai sumber pakan maupun tempat perhentian (untuk meletakkan telur atau menyembunyikan diri dari bahaya) Fungsi yang beragam ini menyebabkan pentingnya memperhatikan tumbuhan berbunga sebagai habitat khusus bagi serangga dan jasad lainnya, dan tumbuhan berbunga sangat penting untuk melestarikan populasi musuh alami di suatu ekosistem seperti agroekosistem terutama di pertanaman yang selama ini dominan sebagai ekosistem monokultur, misalnya tanaman padi (Kurniawati, 2015)

Mengingat peran dari serangga musuh alami yang menguntungkan untuk membantu pengendalian hama dan penyakit ini, maka perlu ada usaha konservasi musuh alami dengan menanam tanaman refugia bersamaan atau mendahului tanaman utama. (Purwantiningsih et al., 2012) sebaiknya tanaman refugia ditanam sebelum tanaman utama agar dapat dimanfaatkan sebagai tempat berlindung dan berkembang biak bagi musuh alami dan serangga pollinator yang berperan dalam polinasi yaitu perantara penyerbukan tanaman. Refugia cocok ditanam di pematang sawah. Penanaman refugia sejajar dengan sinar matahari sehingga tidak menutupi atau mengganggu penyerapan sinar matahari bagi tanaman utama. Untuk melihat bagaimana peningkatan hasil tanaman padi pada lahan suboptimal dengan memanfaatkan refugia sebgaia media utamanya, maka dilakukan penelitian pada 3 hektar lahan pertanian di Kecamatan Pemulutan Kabupaten Ogan Ilir.
Penggunaan refugia tersebut diharapkan bisa meningkatkan hasil pertanian berbasis kearifan lokal, serta mampu menjaga agroekosistem lingkungan secara berkelanjutan. Tujuan penelitian ini adalah untuk mengetahui pemanfaatan refugia sebagai musuh alami organisme pengganggu tanaman padi sehingga mampu meningkatkan produksi padi secara berkesinambungan.

\section{BAHAN DAN METODE}

Penelitian dilakukan dengan memanfaatkan refugia dari jenis bunga matahari (helianthus annuus), wijen (sesamum indicum), bunga kertas (zinnia peruviana), dan kenikir (cosmos caudatus), serta bunga tahi ayam (tagetes $s p$ ). Setelah persiapan lahan untuk selesai, maka semua jenis tanaman refugia di tanam pada tanggul-tanggul sawah secara menyeluruh pada 3 hektar hamparan sawah. Penanam refugia tersebut dilakukan dengan petani pemilik lahan dari jenis bunga matahari 500 gram, wijen 500 gram, bunga kertas 500 gram, kenikir 1000 gram dan bunga tahi ayam 500 gram. Setelah tanaman refugia berumur 2 minggu, maka tanaman padi mulai dipindahkan dari persemaian kepada lahan persawahan. Pengamatan dilakukan dari 1 Hari Setelah Tanam (HST), sampai dengan 119 Hari Setelah Tanam (HST) sebanyak 18 kali pengamatan pada 3 titik berbeda dengan luas hamparan sebanyak 3 hektar. Periode pengamatan dilakukan sekali seminggu antara pukul 07.00-07.30 Waktu Indonesia Barat (WIB), selama 20 menit atau sore hari antara pukul 16.00-16.30 WIB. Penangkapan musuh alami dan hama dilakukan dengan menggunakan sweep net atau jaring ayun, dengan ukuran panjang 80 $\mathrm{cm}$ dan diameter $30 \mathrm{~cm}$, dilengkapi dengan pegangan dari bahan kayu dengan panjang $75 \mathrm{~cm}$. Cara menggunakannya dengan memegang ujung jaring, sementara ujung lingkaran menyentuh tanaman padi, kemudian jaring diayunkan setengah lingkaran. Jaring tersebut terus dilakukan 
pada rumpun padi secara diagonal dengan memanfaatkan 3 titik/hektar, sehingga bisa mewakili semua lahan yang diamati. Teknik pengamatan secara diagonal pada 3 titik/hektar (A, B, dan C), dan masing-masing titik mewakili 10 rumpun padi, sehingga 1 hektar pengamatan sama dengan 30 rumpun padi, cara perhitungan kelimpahan musuh alami dalam 1 hektar adalah (kelimpahan/rumpun padi).

\section{HASIL DAN PEMBAHASAN}

Hasil penelitian pada 3 hektar hamparan sawah pada kelompok Gelora Tani di Desa Pemulutan Ulu, Kecamatan Pemulutan, Kabupaten Ogan Ilir, Sumatera Selatan, dengan menggunakan jenis refugia seperti; bunga matahari (helianthus annuus), wijen (sesamum indicum), bunga kertas (zinnia peruviana), dan kenikir (cosmos caudatus), serta bunga tahi ayam (tagetes $s p)$, maka didapatkan data tentang keberadaan refugia berbanding lurus dengan produksi tanaman padi dalam bingkai kearifan lokal. Kearifan lokal petani dalam menjaga agroekosistem pada lahan suboptimal, merupakan usaha yang harus dilakukan secara terus menerus untuk lingkungan berkelanjutan. Memanfaatkan tanaman pendamping dari jenis refugia, merupakan bentuk kearifan lokal yang harus dilestarikan (Gambar 1).

Pelestarian lingkungan merupakan upaya menjaga keberlangsungan agroekosistem pada lahan suboptimal. Dengan memanfaatkan refugia dari berbagai jenis tumbuhan, diharapkan mampu menjaga arthropoda musuh alami sebagai organisme yang bisa diketemukan pada alam, dan mampu membunuh atau melemahkan hama pada tanaman padi yang bersifat alamiah.

Kelimpahan musuh alami tergantung dari keberagaman jenis tanaman sebagai pencetus datangnya berbagai jenis predator dan parasitoid. Tumbuhan dengan warna mencolok akan mengundang musuh alami, karena jenis tanaman tersebut mampu menyediakan tempat perlindungan, sumber pakan atau sumberdaya yang lainnya. (Allifah et al., 2013)

Penggunaan pestisida secara terus menerus berdampak langsung pada rusaknya lingkungan sehingga kerugian ekologi, ekonomi, dan sosial tidak bisa dihindari. Untuk mengurangi efek lingkungan yang ditimbulkan akibat penggunaan bahan kimia, maka Pengendalian HamaTerpadu (PHT) bisa dilakukan dengan memanfaatkan agen hayati berupa tanaman refugia (Darmania, 2017).

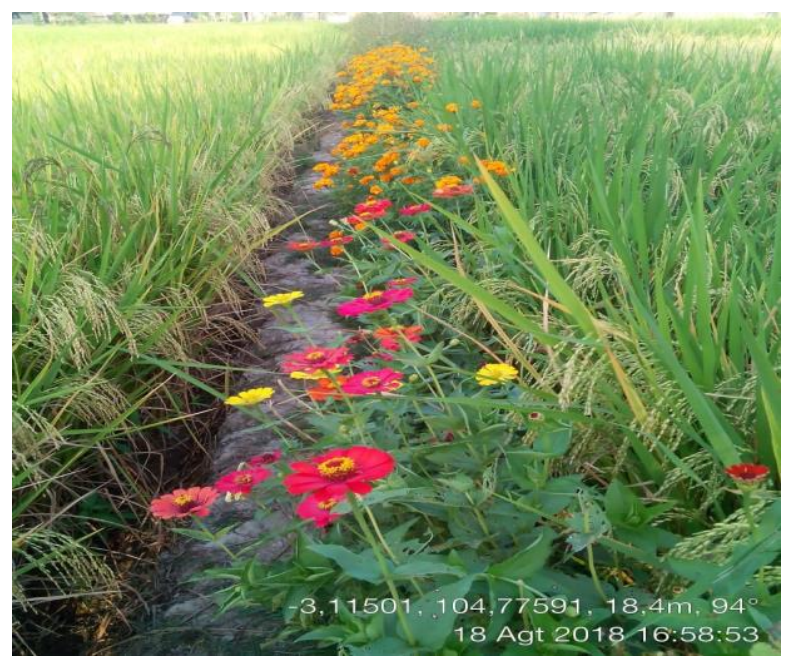

Gambar 1. Refugia dari jenis bunga kertas, tahi ayam dan kenikir 
Untuk mengetahui intensitas dan tanaman padi seluas 3 hektar hamparan dari kelimpahan musuh alami dan hama pada jenis Ciherang dan IR 42 (Tabel 1):

Tabel 1. Jumlah kelimpahan musuh alami dan hama (individu/minggu)

\begin{tabular}{|c|c|c|c|c|c|c|c|}
\hline No & $\begin{array}{c}\text { Tanggal } \\
\text { Pengamatan }\end{array}$ & $\begin{array}{c}\text { Umur } \\
\text { Tanam } \\
\text { (HST) }\end{array}$ & $\begin{array}{l}\text { Jumlah } \\
\text { Musuh } \\
\text { Alami }\end{array}$ & $\begin{array}{l}\text { Rata-rata } \\
\text { /Rumpun }\end{array}$ & $\begin{array}{l}\text { Jumlah } \\
\text { Hama }\end{array}$ & $\begin{array}{l}\text { Rata-rata } \\
\text { /Rumpun }\end{array}$ & Jenis Hama/Musuh Alami \\
\hline 01 & $01-05-2018$ & 1 & - & - & - & - & Musuh Alami : \\
\hline 02 & 08-05-2018 & 7 & - & - & - & - & 1. Kumbang kubah (micraspis \\
\hline 03 & $12-05-2018$ & 14 & - & - & - & - & $s p)$. \\
\hline 04 & $19-05-2018$ & 21 & 9 & 0,3 & 6 & 0,2 & 2. Tomcat (paederus littoralis) \\
\hline 05 & $26-05-2018$ & 28 & 15 & 0,5 & 4 & 0,13 & 3. Capung jarum sawah \\
\hline 06 & 02-06-2018 & 35 & 16 & 0,53 & 2 & 0,067 & $\begin{array}{l}\text { (zygoptera sp) } \\
4 \text { Belalano semb: }\end{array}$ \\
\hline 07 & 09-06-2018 & 42 & 18 & 0,6 & 2 & 0,067 & $\begin{array}{l}\text { 4. Belarang semban } \\
\text { (stagmomantis caroli }\end{array}$ \\
\hline 08 & $13-06-2018$ & 46 & 20 & 0,67 & 2 & 0,067 & 5. Laba-laba pemburu (oxyopes \\
\hline 09 & 23-06-2018 & 56 & 21 & 0,7 & 6 & 0,2 & javanus) \\
\hline 10 & $30-06-1018$ & 63 & 22 & 0,73 & 2 & 0,067 & 6. Laba-laba pembuat Jaring \\
\hline 11 & 07-07-2018 & 70 & 23 & 0,76 & 4 & 0,13 & (tetragnatha maxillosa) \\
\hline 12 & $14-07-2018$ & 77 & 35 & 0,83 & 4 & 0,13 & Jenis Hama : \\
\hline 13 & 21-07-2018 & 84 & 30 & 1 & 5 & 0,16 & 1. Hama putih/penggulung daun \\
\hline 14 & 28-07-2018 & 91 & 31 & 1,03 & 4 & 0,13 & (nymphula depunctalis) \\
\hline 15 & 04-08-2018 & 98 & 33 & 1,1 & 5 & 0,5 & 2. Hama putih palsu/pelipat \\
\hline 16 & $11-08-2018$ & 105 & 34 & 1,13 & 4 & 0,13 & un (cnaphlacorosts \\
\hline 17 & $18-08-2018$ & 112 & 35 & 1,16 & 2 & 0,067 & 3. Penggerek batang padi putih \\
\hline \multirow[t]{2}{*}{18} & $25-08-2018$ & 119 & 36 & 1,2 & 2 & 0,067 & (tryporyza innotata) \\
\hline & & & & & & & $\begin{array}{l}\text { 4. Walang sangit (leptocorisa } \\
\text { acuta) }\end{array}$ \\
\hline
\end{tabular}

Sumber data primer diolah

Kelimpahan musuh alami meningkat pada minggu 12 atau pada saat tanaman padi berusia 77 Hari Setelah Tanam (HST), kelimpahan musuh alami tersebut 5 kali lipat dibandingkan dengan 21 HST (Tabel 1). Intensitas musuh alami terjadi karena tanaman refugia yang ditanam pada tanggul-tanggul persawahan sudah berbunga, sehingga mengundang parasitoid dan predator untuk datang pada tumbuhan berbunga tersebut. Puncak kelimpahan hama terjadi pada saat usia tanaman 119 HST atau 18 minggu pasca tanam. Faktor pendukung tingginya kelimbahan musuh alami adalah tanaman refugia.

Musuh alami dan hama mulai berdatangan saat usia tanaman 21 HST. pada kondisi ini ditemukan musuh alami sebanyak 9 ekor pada 30 rumpun padi yang diamati dengan rata-rata 17-25 batang/rumpun, sehingga rata-rata $9 / 30=0,3$ ekor/rumpun padi. Sementara untuk hama ada 6 ekor untuk rumpun yang sama sehingga rata-rata $6 / 30=0,2$ ekor/rumpun.

Pada saat umur padi 28 HST ditemukan 15 ekor musuh alami atau rata-rata 0,5/rumpun, sementara untuk hama ada 4 ekor atau rata-rata 0,13/rumpun. Pada saat umur padi 35 HST ditemukan 16 ekor musuh alami atau rata-rata 0,53/rumpun padi, sementara untuk hama ada 2 ekor atau rata-rata 0,4/rumpun. Pada saat umur padi 42 HST ditemukan 18 ekor musuh alami atau rata-rata 0,6/rumpun, sementara untuk hama ada 2 ekor atau rata-rata 0,067/rumpun.

Kelimpahan hama pada umur padi 42, 63, 112 dan 119 HST berada pada level yang sama yaitu rata-rata 2 ekor atau 0,067/rumpun padi. Sementara itu, pada saat umur tanam berada 49 HST ada 20 ekor musuh alami atau rata-rata 0,67/rumpun padi, umur tanam 56 HST ada 21 ekor musuh alami atau rata-rata 0,7/rumpun padi, umur tanam berada 63 HST ada 22 ekor 
musuh alami atau rata-rata 0,73/rumpun padi, umur tanam berada 70 HST ada 23 ekor musuh alami atau rata-rata 0,76/rumpun padi, umur tanam berada 77 HST ada 35 ekor musuh alami atau rata-rata 0,83/rumpun padi, umur tanam 84 HST ada 30 ekor musuh alami atau rata-rata 1/rumpun padi, umur tanam 91 HST ada 31 ekor musuh alami atau rata-rata 1,03/rumpun padi, umur tanam 98 HST ada 33 ekor musuh alami atau rata-rata 1,1/rumpun padi, umur tanam 105 HST ada 34 ekor musuh alami atau rata-rata 1,13/rumpun padi, umur tanam 112 HST ada 35 ekor musuh alami atau rata-rata 1,16/rumpun padi, dan pada saat umur tanam berada pada 119 HST maka saat inilah musuh alami paling banyak diketemukan yaitu 36 ekor atau rata-rata 1,2/rumpun padi.

Dengan demikian dapat disimpulkan bahwa keberadaan tumbuhan berbunga dari jenis refugia sangat penting untuk melestarikan populasi musuh alami di suatu agroekosistem. Sementara itu, populasi hama dari jenis Hama putih/penggulung daun (nymphula depunctalis), Hama putih palsu/pelipat daun (cnaphlacorosis medinalis), Penggerek batang padi putih (Tryporyza innotata), dan Walang sangit (leptocorisa acuta) pada umur tanam 35, 42, 63, 112 dan 119 HST, kelimpahan hama sebesar 2 ekor atau rata-rata 0,067/rumpun padi. Sementara pada saat umur padi 56 HST ditemukan 6 ekor atau rata-rata 0,2/rumpun padi, umur padi 70, 77, 91, dan 105 HST kelimpahan hama masing-masing 4 ekor atau rata-rata 0,13 /rumpun padi.

Selanjutnya, pada saat umur padi 84 dan 98 HST diketemukan 5 ekor hama atau rata-rata $0,5 /$ rumpun padi. Jumlah hama di lahan tersebut lebih rendah dari musuh alami atau predator, hal ini dikarenakan lahan ini memiliki keragaman refugia dari jenis bunga matahari (helianthus annuus), wijen (sesamum indicum), bunga kertas (zinnia peruviana), dan kenikir (cosmos caudatus) serta bunga tahi ayam (tagetes $s p$ ) sebagai tempat berlindung maupun mendapatkan makanan.
Intensitas kelimpahan musuh alami atau predator dari jenis Kumbang kubah (micraspis sp.), Tomcat (paederus littoralis), Capung jarum sawah (zygoptera sp), Belalang sembah (stagmomantis carolina), Laba-laba pemburu (oxyopes javanus), dan Laba-laba pembuat Jaring (tetragnatha maxillosa) sebanyak 378 ekor. Banyaknya jumlah parasitoid dan predator tersebut didukung oleh tanaman pendamping seperti refugia yang di tanam pada tanggul-taggul persawahan.

Sementara itu, intensitas hama dari jenis Hama putih/penggulung daun (nymphula depunctalis), Hama putih palsu/pelipat daun (cnaphlacorosis medinalis), Penggerek batang padi putih (tryporyza innotata), dan Walang sangit (leptocorisa acuta) sebanyak 54 ekor. Keberadaan hama pada rumpun padi hanya $14,3 \%$ dari jumlah musuh alami yang ditemukan pada rumpun yang sama. Hal ini dikarenakan parasitoid dan predator tersebut mampu membunuh hama yang akan mengganggu tanaman sekitar refugia. OLeh karena itu tanaman refugia memiliki kemampuan dalam menyokong mekanisme sistem yang meliputi perbaikan ketersediaan makanan alternatif seperti nektar, serbuk sari, dan embun madu; menyediakan tempat berlindung atau iklim mikro yang digunakan serangga predator untuk bertahan melalui pergantian musim atau berlindung dari faktor-faktor ekstremitas lingkungan atau pestisida; dan menyediakan habitat untuk inang atau mangsa alternatif (Landis, D.A., S.D. Wratten, 2000). Sebagai tanaman yang menyediakan tempat berlindung dan makanan memadai, maka refugia dapat diandalkan sebagai pemicu datangnya berbagai jenis musuh alami yang sangat bermanfaat untuk tanaman padi. Selanjutnya untuk melihat peningkatan hasil panen/hektar, maka dilakukan pengubinan pada 3 titik lokasi yang berbeda (A,B dan C).

\section{Pengubinan}

Untuk mengetahui jumlah hasil panen/hektar maka dilakukan pengubinan 
pada 3 titik hamparan (Gambar 2), kemudian melakukan perhitungan rata-rata dalam floating $\mathrm{A}, \mathrm{B}$ dan $\mathrm{C}$ sebagai berikut :

Hasil Ubinan $\mathbf{x} \frac{\text { Luasan perhektar }}{\text { Jumlah luasan ubinan }}=$ Jumlah hasil perhektar
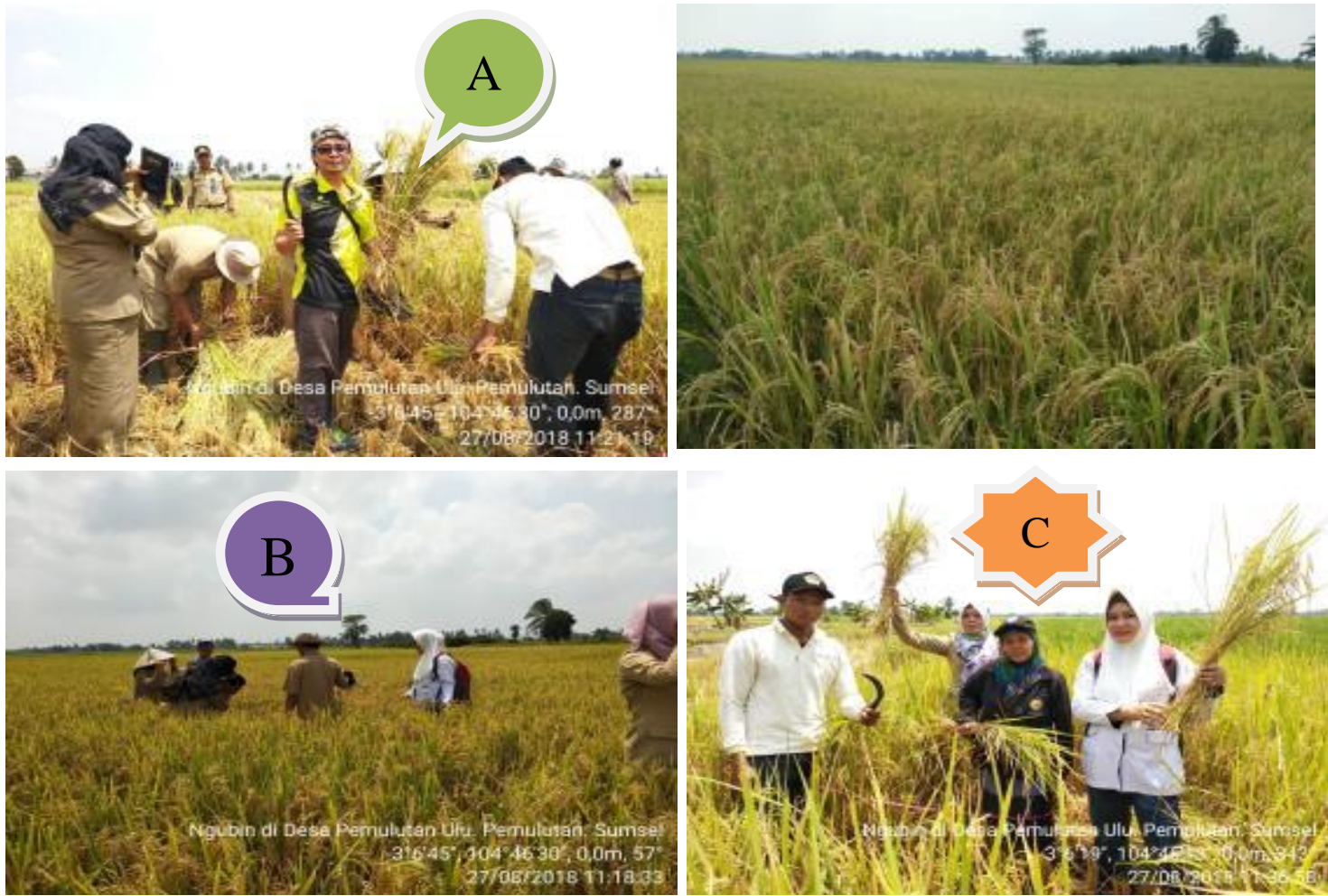

Gambar 2. Pengubinan, titik A dan C varietas Ciherang, titik B varietas IR 42

Pada floating A dilakukan pengubinan pada varietas Ciherang dengan luas areal 2,5 X 2,5 =6,25 $\mathrm{m}^{2}$. Metode pengubinan ini dihitung dari panjang malai, jumlah bulir, jumlah anakan, jumlah rumpun, dan berat ubinan, maka diperoleh hasil untuk 1 hektar adalah $=10.000 / 6,25=1.600$. Jumlah hasil ubinan untuk $6,25 \mathrm{~m}^{2}$ adalah $5 \mathrm{~kg}$, sehingga rata-rata produksi padi untuk areal 1 hektar adalah 5 x 1.600 $=8.000 \mathrm{~kg}$ atau 8 ton/hektar.

Floating B dilakukan pengubinan untuk varietas IR42 dengan luas dan metode yang sama yaitu luas areal 2,5 X 2,5=6,25 $\mathrm{m}^{2}$ maka diperoleh hasil untuk 1 hektar adalah $=10.000 / 6,25=1.600$. Jumlah hasil ubinan untuk $6,25 \mathrm{~m}^{2}$ adalah $5,2 \mathrm{~kg}$, sehingga rata-rata produksi padi untuk areal 1 hektar adalah $5,2 \times 1.600=8.300 \mathrm{~kg}$ atau 8,3 ton/hektar. Pada floating $\mathrm{C}$ dengan metode dan luas areal ubinan yang sama dari varietas Ciherang, maka dihasilkan 5,1 $\mathrm{kg} / 6,25 \mathrm{~m}^{2}$. Sehingga rata-rata produksi padi/hektar adalah $5,1 \mathrm{~kg} \times 1.600=8.100 \mathrm{~kg}$ atau 8,1 ton/hektar .

Pada tahun 2017, masyarakat di Desa Pemulutan Ulu dengan kelompok tani yang sama (Gelora Tani), masih menggunakan model konvensional pada saat tanaman padi terserang hama. Mulai tahun 2018 beralih dari modernitas dengan segala resikonya, kepada tradasional dan berwawasan lingkungan. Dengan membandingkan lahan dan hamparan yang sama, serta penggunaan varietas Ciherang dan IR 42, maka diperoleh hasil 5,4 ton/hektar atau 16,2 ton untuk 3 hektar. Jika dibandingkan antara tahun 2017 dan 2018, dengan menggunakan varietas yang sama, produksi padi rata-rata 8,1 ton/hektar atau 
mengalami peningkatan sebesar $15,1 \%$ / hektar. Tabulasi data rata-rata produksi tanaman padi/hektar pada tahun 2018 (Tabel 2):

Tabel 2. Jumlah rata-rata produksi tanaman padi/hektar 2018

\begin{tabular}{|c|c|c|c|c|}
\hline $\mathrm{No}$ & Floating & Deskripsi & Varietas & Jumlah \\
\hline 01 & Titik A & $\begin{array}{l}\text { 1. Floating A dilakukan pengubinan dengan } \\
\text { luas } 2,5 \times 2,5=6,25 \mathrm{~m}^{2} \\
\text { 2. Luasan perhektar }=10.000 / 6,25=1.600 \\
\text { 3. Hasil ubinan } 5 \mathrm{~kg} \times 1.600=8.000 \mathrm{~kg}\end{array}$ & Ciherang & 8 ton / hektar \\
\hline 02 & Titik B & $\begin{array}{l}\text { 1. Floating B dilakukan pengubinan dengan } \\
\text { luas } 2,5 \times 2,5=6,25 \mathrm{~m}^{2} \\
\text { 2. Luasan perhektar }=10.000 / 6,25=1.600 \\
\text { 3. Hasil ubinan } 5,2 \mathrm{~kg} \times 1.600=8.300 \mathrm{~kg}\end{array}$ & IR 42 & 8,3 ton / hektar \\
\hline 03 & Titik C & $\begin{array}{l}\text { 1. Floating C dilakukan pengubinan dengan } \\
\text { luas } 2,5 \times 2,5=6,25 \mathrm{~m}^{2} \\
\text { 2. Luasan perhektar }=10.000 / 6,25=1.600 \\
\text { 3. Hasil ubinan } 5,1 \mathrm{~kg} \times 1.600=8.100 \mathrm{~kg}\end{array}$ & Ciherang & 8,1 ton / hektar \\
\hline
\end{tabular}

Sumber data primer diolah

\section{KESIMPULAN}

Refugia merupakan tumbuhan berbunga yang mampu menarik parasitoid dan predator yang dapat bermanfaat sebagai Organisme Pengganggu Tanaman (OPT). Keberadaan beragam musuh alami sebagai salah satu komponen ekosistem pertanian diharapkan dapat mempertahankan kelengkapan komponen rantai makanan, sehingga mampu pula menciptakan kestabilan agroekosistem pada lahan suboptimal.

Keberadaan refugia yang ditanam pada tanggul-tanggul persawahan berdampak langsung pada kelimpahan musuh alami. Parasitoid dan predator mulai mengalami peningkatan pada minggu 12 atau pada saat tanaman padi berusia 77 Hari Setelah Tanam (HST). Kelimpahan musuh alami tersebut mencapai 5 kali lipat dibandingkan dengan $21 \mathrm{HST}$. Intensitas musuh alami terjadi karena tanaman refugia yang ditanam pada pinggiran persawahan sudah berbunga, sehingga mengundang musuh alami untuk datang pada tumbuhan berbunga tersebut. Puncak kelimpahan hama terjadi pada saat usia tanaman 119 HST atau 18 minggu pasca tanam.

$$
\text { Refugia sebagai tempat }
$$
perlindungan dan sumber pakan untuk keanekaragam musuh alami/predator akan menekan tingkat populasi hama pada tanaman padi. Tahun 2017, petani masih mengandalkan pestisida untuk membasmi hama pada tanaman padi. Produksi tanaman padi pada tahun tersebut dengan menggunakan varietas Ciherang dan IR 42, diperoleh hasil 5,4 ton/hektar atau 16,2 ton untuk 3 hektar. Mulai tahun 2018 beralih dari konvensional dengan segala resikonya, kepada tradasional sebagai bentuk kearifan lokal dan berwawasan lingkungan. Dari hasil pengubinan didapatkan hasil rata-rata 8,1 ton/hektar, atau mengalami peningkatan sebesar $15,1 \%$ /hektar.

Dengan membandingkan lahan dan hamparan yang sama, serta penggunaan varietas Ciherang dan IR 42, maka diperoleh hasil 5,4 ton/hektar atau 16,2 ton untuk 3 hektar. Jika dibandingkan antara tahun 2017 dan 2018, dengan menggunakan varietas yang sama, produksi padi rata-rata 8,1 ton/hektar atau mengalami peningkatan sebesar $15,1 \%$ /hektar

\section{DAFTAR PUSTAKA}

Addina L, Yanuwiadi B, Gama Z panata \& Leksono A setyo. 2013. Efek perpaduan beberapa tumbuhan liar di sekitar area pertanaman padi dalam menarik arthropoda musuh alami dan hama. El-Hayah, 3(2), pp.71-81. 
Alavanja MCR, Hoppin JA \& Kamel F. 2004. Health effects of chronic pesticide exposure: cancer and neurotoxicity. Annual Review of Public Health, 25(1), pp.155-197.

Allifah ANA, Yanuwiadi B, Gama ZP \& Leksono AS. 2013. Refugia sebagai mikrohabitat untuk meningkatkan peran musuh alami di lahan pertanian. Prosiding FMIPA Universitas Pattimura, (2010), pp.113-116.

Altieri MA \& Letourneau DK. 1982. Vegetation management and biological control in agroecosystems. 1, pp.405-430.

Arcury TA \& Quandt SA. 2003. Pesticides at work and at home: Exposure of migrant farmworkers. Lancet, 362(9400), p.20-21.

Darmania U. 2017. Pemanfaatan Tanaman Refugia untuk Mengendalikan Hama dan Penyakit Tanaman Padi. In Informasi Pengkajian dan Disemninasi Inovasi Teknologi Informasi. pp. 29-45.

Kurniawati N. 2015. Peran Tumbuhan Berbunga Sebagai Media Konservasi Artropoda Musuh Alami. Jurnal
Perlindungan Tanaman Indonesia, 19(2), pp.53-59.

Landis DA, SD Wratten dan GMG. 2000. Habitat Management to Conserve Natural Enemies of Arthropod Pests in Agriculture. Annu. Rev. Entomol, 45, pp.175-201.

Mahmud T. 2006. Identifikasi serangga di sekitar tumbuhan kangkungan (Ipomoeas crassicaulis roob.). Universitas Islam Negri Malang.

Purwantiningsih B, Leksono AS \& Yanuwiadi B. 2012. Kajian Komposisi Serangga Polinator Pada Tumbuhan Penutup Tanah Di Poncokusumo-Malang. 17, pp. 165-172.

Sam KG, Andrade HH, Pradhan L, Pradhan A, Sones SJ, Rao PGM, et al. 2008. Effectiveness of an educational program to promote pesticide safety among pesticide handlers of South India. International Archives of Occupational and Environmental Health, 81(6), pp.787-795.

Wahyuni R. 2013. Peningkatan keragaman tumbuhan berbunga sebagai daya tarik predator hama padi. Universitas Sebelas Maret. 